\title{
Combination of apoptin with photodynamic therapy induces nasopharyngeal carcinoma cell death in vitro and in vivo
}

\author{
XIAOYONG FANG, PING WU, JINYUN LI, LIN QI, YAOYUN TANG, WEIHONG JIANG and SUPING ZHAO \\ Department of Otolaryngology, Xiangya Hospital, Central South University, Changsha 410008, Hunan, P.R. China
}

Received May 22, 2012; Accepted August 13, 2012

DOI: $10.3892 / o r .2012 .2044$

\begin{abstract}
Photodynamic therapy has been developed as a viable treatment for cancer, while apoptin is an apoptosis-inducing protein. This study was undertaken to evaluate the feasibility and efficacy of apoptin with photodynamic therapy (PDT) in the treatment of nasopharyngeal carcinoma (NPC). RT-PCR and western blotting were used to detect the expression of apoptin in CNE-2 NPC cells. MTT and flow cytometry analysis were used to detect cell proliferation and cell apoptosis, respectively. Transmission electron microscopy was used to observe cell structures. Hematoxylin and eosin staining was used to observe the xenograft morphology. The expression of apoptin was analyzed by RT-PCR and western blotting in CNE-2 cells stably transfected with PVP3 plasmid. Apoptin restrained cell proliferation and enhanced cell apoptosis compared to controls. Furthermore, we demonstrated that apoptin augmented the effect of PDT with stronger cell proliferation restraint and cell apoptosis and induced severe ultrastructural morphology changes compared to controls. Additionally, we found that the combination of apoptin and PDT produced the strongest inhibition of xenograft growth and tumor necrosis in in vivo experiments. Collectively, we show that apoptin in combination with PDT has a better therapeutic effect in NPC than PDT therapy or apoptin gene therapy alone.
\end{abstract}

\section{Introduction}

NPC is one of the most common malignant tumors in southern China and southeast Asia with incidence rates of 20-50 per 100,000 (1). The most effective treatment for NPC is radiotherapy, which achieves an overall 5-year survival rate of $65 \%$ (2). Nevertheless, NPC local recurrence remains a serious barrier to successful treatment in many cases. Since overfull radiotherapy easily leads to undesirable complications, development of novel therapeutic approaches to NPC is necessary.

Correspondence to: Dr Suping Zhao, Department of Otolaryngology, Xiangya Hospital, Central South University, Xiangya Road 87, Changsha 410008, Hunan, P.R. China

E-mail: xyxzsp@126.com

Key words: photodynamic therapy, apoptin, nasopharyngeal carcinoma, apoptosis
PDT is a minimally invasive modality in the treatment of a variety of malignant tumors. It is a form of photochemotherapy that uses a photosensitizer, light and oxygen. PDT involves the targeting of cells or tissues that have been sensitized to light by administration of a photosensitizing agent. Photosensitizers used in this process include 5-aminolevulinic acid (5-ALA) and its lipophilic derivative, methyl-aminolevulinate (MAL) (3). Because of its high selectivity and low toxicity, attention has been focused on its application in PDT (4-8).

Apoptosis is the main way for PDT-induced cell death. PDT can lead plasma membrane and lysosome to necrosis, whereas mitochondrial activity can lead to programmed cell death, including the extrinsic death pathway (death receptor-dependent) and the intrinsic pathway (mitochondria-dependent). In the extrinsic pathway, apoptosis is stimulated upon the binding of specific ligands to death receptors triggering the recruitment of the adaptor Fas- and TNFR-associated death domain protein (FADD and TRADD) and initiator caspase- 8 into a death-inducing signaling complex (DISC). In the intrinsic pathway, various stress conditions cause the release of cytochrome $\mathrm{c}$ into the cytosol, a process that is tightly regulated by pro- and anti-apoptotic proteins of the Bcl-2 family. Once released, cytochrome c binds to the adapter protein Apaf-1, which enables the activation of the initiator caspase- 9 in a high-molecular-weight complex, called the apoptosome (9-11). Generally, mitochondrion plays an important role in PDT initiating and executing apoptosis in several types of cells.

Apoptin is a small apoptosis-inducing protein derived from chicken anemia virus (CAV) (12). It is also commonly called VP3, which is a $14-\mathrm{kDa}$ non-structural protein $(13,14)$. Apoptin can induce programmed cell death in a broad range of transformed and cancer cells but not in nontransformed or primary cells $(15,16)$. It was reported that apoptin can induce selective death of a variety of malignant cells and transformed cells, including melanoma, lymphoma, hepatoma, colon carcinoma, breast and lung cancer $(17,18)$. Many human tumor cell lines were shown to be susceptible to apoptin. However, apoptin does not induce apoptosis in normal cells such as human endothelial cells and hepatocytes (17). Apoptin induces tumor cell death mainly through mitochondrial pathway independently of p53 (19). In this pathway, apoptin could trigger cytochrome $\mathrm{c}$ release and the activation of caspase-9 (20).

In this study, we supposed that apoptin would potentiate PDT therapy in NPC. We evaluated efficacy of apoptin with 
PDT treatment in vivo and in vitro experiment and confirmed apoptin to have synergic efficiency in PDT.

\section{Materials and methods}

Cell culture. NPC cell CNE-2 used in this study was obtained from Cancer Research Institute, Central South University. CNE-2 cells were cultured in RMPI-1640 medium (HyClone, Thermo Scientific, USA) supplemented with $10 \%$ of fetal bovine serum (FBS, Hyclone) and was maintained at $37^{\circ} \mathrm{C}$ in an incubator at a humidified atmosphere with $5 \% \mathrm{CO}_{2}$ in air. VP3-transfected CNE-2 cells and mock vector-transfected as control cells were maintained in a medium supplemented with $10 \%$ FBS and G418 (500 $\mu \mathrm{g} / \mathrm{ml}$ for CNE-2 clone selection).

Plasmids and stable transfection. The vector pcDNA ${ }^{\mathrm{TM}} 3.1(-)$ and control plasmid pcDNA3.1/CAT were purchased from Invitrogen. The full-length cDNA of VP3 gene was amplified by PCR and cloned into pcDNA3.1(-) to form expression vector PcDNA3.1(-)VP3-Myc (PVP3). The vector was transformed into competent $E$. coli that was cultured in the selecting medium with $50 \mu \mathrm{g} / \mathrm{ml}$ of spectinomycin. The selected plasmid was confirmed by DNA sequencing. For stable transfection, CNE- 2 cells seeded in 24-well plates were transfected with $0.8 \mu \mathrm{g}$ of either PVP3 or pcDNA3.1(-) using Lipofectamine ${ }^{\mathrm{TM}} 2000$ (Invitrogen, CA, USA) according to the manufacturer's instructions. After no less than 14 days of selection in RPMI-1640 containing 10\% FBS and G418 (500 $\mu \mathrm{g} / \mathrm{ml})$, individual G418-resistant colonies were isolated and expanded. The expression of VP3 was verified by reverse transcription-polymerase chain reaction (RT-PCR) and western blotting.

Reverse transcription-PCR analysis. TRIzol reagent (Invitrogen) was used for total RNA extraction. After confirmation of the RNA integrity on an agarose gel, total RNA was dissolved in RNase-free water. The cDNA was synthesized from $2 \mu \mathrm{g}$ of total RNA using M-MuLV RT Transcriptase and oligo(dT) (Fermentas Life Sciences). For PCR, $2 \mu 1$ of cDNA products was mixed with PCR mix buffer (Tiangen, China) and $0.1 \mu \mathrm{mol}$ concentrations of VP3 PCR primers, which synthesized according to the cDNA sequence in GenBank. The primer sequences utilized in this study are VP3 forward: 5'-CGGAATTCATGAACGCTCTCC AAGAAG-3',VP3 reverse: 5'-CGGAATTCTTACAGTCTTATA CG-3'; GAPDH forward: 5'-CAAGGTCATCCATGACAACTTT G-3', GAPDH reverse: 5'-CAAGGTCATCCATGACAACTT TG-3'. RT product was amplified using the following conditions: $95^{\circ} \mathrm{C}$ for $5 \mathrm{~min}$; then 30 cycles at $95^{\circ} \mathrm{C}$ for $45 \mathrm{sec}, 56^{\circ} \mathrm{C}$ for $45 \mathrm{sec}$ and $72^{\circ} \mathrm{C}$ for $45 \mathrm{sec}$; and an extension at $72^{\circ} \mathrm{C}$ for $5 \mathrm{~min}$. PCR product was electrophoresed on $1.5 \%$ agarose gel, FluorChem FC2 (San Leandro, CA) was applied for detection of the intensity of bands. PCR experiments were repeated three times.

Western blotting. Total protein $(40 \mu \mathrm{g})$ was resolved by SDS-PAGE and transferred onto a PVDF membrane. The membranes was incubated with primary antibody: anti-VP3 (Santa Cruz, 1:200), then goat anti-mouse IgG horseradish peroxidase (Beyotime, Beijing, China, 1:2000 dilution) was used as secondary antibody. Bands were visualized by employing the ECL Plus Detection system (Beyotime). Signal intensity was analyzed using GeneTools software (Syngene, Frederick, MD,
USA). The level of $\beta$-actin was used as a loading control. The results of western blot analysis represented the average of three individual experiments.

Photodynamic therapy (PDT). For cells, after incubated with 5-ALA (Sigma Chemical Co., $1 \mathrm{mmol} / \mathrm{l}$ ) for $6 \mathrm{~h}$, cells received PDT treatment with different laser energy density $(630 \mathrm{~nm}, 1,3$ and $6.25 \mathrm{~J} / \mathrm{cm}^{2}$ ). The nude mice received $20 \% 5$-ALA at a dose of $100 \mathrm{mg} / \mathrm{kg}$, following by PDT $\left(630 \mathrm{~nm}, 100 \mathrm{~J} / \mathrm{cm}^{2}, 100 \mathrm{~mW} /\right.$ $\mathrm{cm}^{2}$ ) at 3-3.5 h later (21). The diameter of the irradiating laser beam entirely covered the tumor.

Cell proliferation. Cell proliferation was analyzed using the 3-(4,5-dimethylthiazol-2-yl)-2,5-diphenyl-tetrazolium bromide (MTT) assay (Beyotime). Briefly, the cells $\left(5 \times 10^{3}\right.$ cells/well) were planted in the 96 -well culture plates overnight at $37^{\circ} \mathrm{C}$. After 8-h PDT treatment, cell proliferation was monitored by using MTT. MTT reagent was added into each well, incubating for $4 \mathrm{~h}$, then MTT reagent was removed and DMSO was added per well. After shaking for $10 \mathrm{~min}$, optical densities (OD) were determined on a microtiter plate reader at $570 \mathrm{~nm}$. Three independent experiments were done. Proliferation was calculated using the following equation: Proliferation $(\%)=1$ - (OD control group - OD treatment group)/OD control group $\mathrm{x} 100 \%$.

Flow cytometry analysis of cell apoptosis. Cell apoptosis was detected by Annexin V-FITC apoptosis detection kit (Beyotime). The cells were seeded into 6 -well culture plates at $2 \times 10^{5}$ per well. After harvested at $6 \mathrm{~h}$ after PDT treatment, cells were stained using Annexin-V-FITC for 10 min at room temperature, then were stained using propidium iodure (PI) for $10 \mathrm{~min}$ in dark. The cells were analyzed on a FSCAN flow cytometer (BD Biosciences, USA) immediately. All samples were assayed in triplicate.

Transmission electron microscopy (TEM). To identify cell morphology, TEM was performed on the Mock vector or PVP3 vector transfected CNE- 2 cells at $6 \mathrm{~h}$ after PDT treatment. The cells were incubated with 5-ALA at the concentration of $1 \mathrm{mmol} / \mathrm{l}$ for $6 \mathrm{~h}$ before PDT treatment at the intensity of $3 \mathrm{~J} / \mathrm{cm}^{2}$. Fixed cells were postfixed in $2 \%$ glutaraldehyde, dehydrated in graded alcohol, and flat embedded in Epon 812. After stained with uranyl acetate and lead citrate, ultrathin sections (100 nm) were examined under an electron microscopy (H-7500, Lympus, Japan).

Animal experiments and tumor model. Male Balb/c nude mice, 6-8 weeks old and weighing 18-22 g $(\mathrm{n}=32)$ were used. The mice were purchased from the Institute of Laboratory Animal Sciences of the Chinese Academy of Medical Sciences (CAMS). The study was approved by the Ethics Committee for Biomedical Research of Xiang Ya School of Medicine, Changsha, China. All the animals were bred at the Animal Center of Xiangya Medical School. Mock- or PVP3-vector stably transfected CNE-2 cells were cultured and implanted subcutaneously $\left(1 \times 10^{6}\right)$ in the nude mice. When tumor grew to a size of 5-8 $\mathrm{mm}$ in diameter, the animals were divided into four groups (8 animals per group), including Mock group, PVP3 group, Mock + PDT group and PVP3 + PDT group. At 14 days 


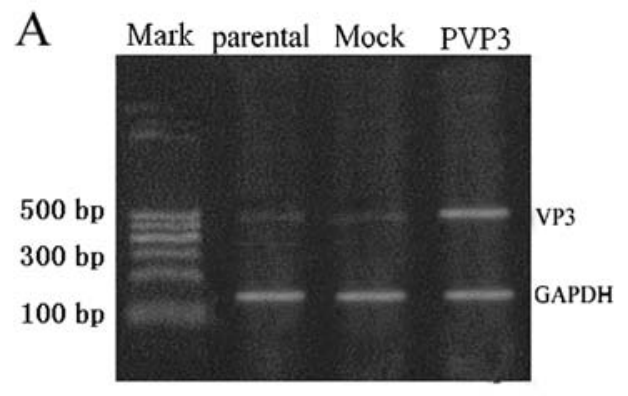

B

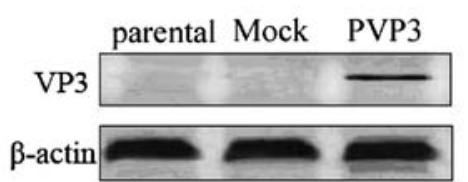

Figure 1. Apoptin expression in stably transfected CNE-2 cells. (A) RT-PCR analysis of apoptin expression in parental, Mock vector or PVP3 vector transfected CNE-2 cells are presented. (B) Western blot results of apoptin expression in parental, Mock vector or PVP3 vector transfected CNE-2 cells are presented.

after irradiation, the mice in groups were sacrificed. Tumor sizes and weights were recorded on days $0,3,7$ and 14 .

Hematoxylin and eosin $(H \& E)$ staining. A part of each tumor was excised and fixed in $3.7 \%$ formaldehyde for routine paraffin embedding. A series of sections were excuted for each specimen, laid on polylysine-coated glass slides, then dried on a hot plate, and $H \& E$ staining was carried out on at least three sections of each specimen.

Statistical analyses. All statistical analyses were carried out using SPSS for Windows version 13.0 (SPSS). Student's t-test and one-way analysis of variance (ANOVA) were used to analyze the data. All cell culture experiments were performed in triplicate. Data are presented as mean \pm standard deviation (SD). Differences were considered statistically significant for $\mathrm{P}<0.05$.

\section{Results}

Apoptin is expressed in PVP3 stable transfection CNE-2 cells. In order to express apoptin in CNE-2 cells, we applied PVP3 plasmid to transfect CNE-2 cells. RT-PCR and western blotting were used to detect apoptin expression. RT-PCR analysis confirmed apoptin expression in PVP3 transfected CNE-2 cells while no apoptin expression in mock vector transfected CNE-2 cells (Fig. 1A). As shown in Fig. 1B, western blot analysis also demonstrated that apoptin was expressed in PVP3-CNE-2 cells while not in Mock-CNE-2 cells.

Apoptin restrains cell proliferation and enhances cell apoptosis. We observed an important change of cell proliferation and apoptosis induced by apoptin in CNE-2 cells. We used PVP3 vector and Mock vector treated CNE-2 cells at different time intervals $(24,48$ and $72 \mathrm{~h})$ for transient transfection. The expression of apoptin was detected by western blotting and reached the strongest expression at $72 \mathrm{~h}$ (Fig. 2A). As shown in Fig. 2B, after transient transfection, Mock-CNE-2 cells
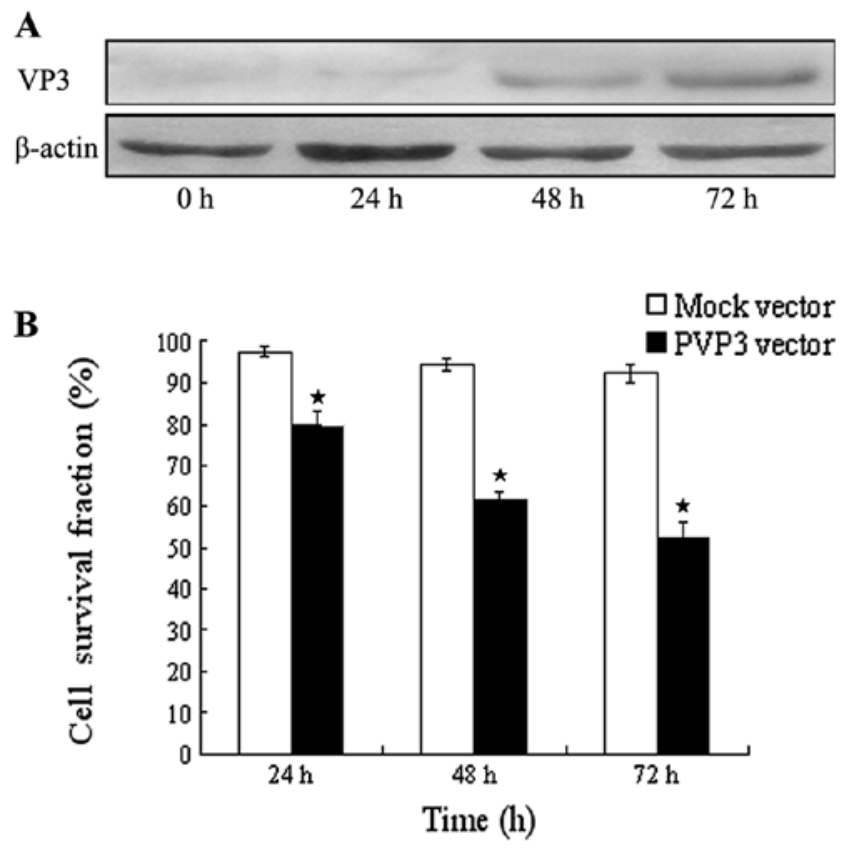

$\mathbf{C}$

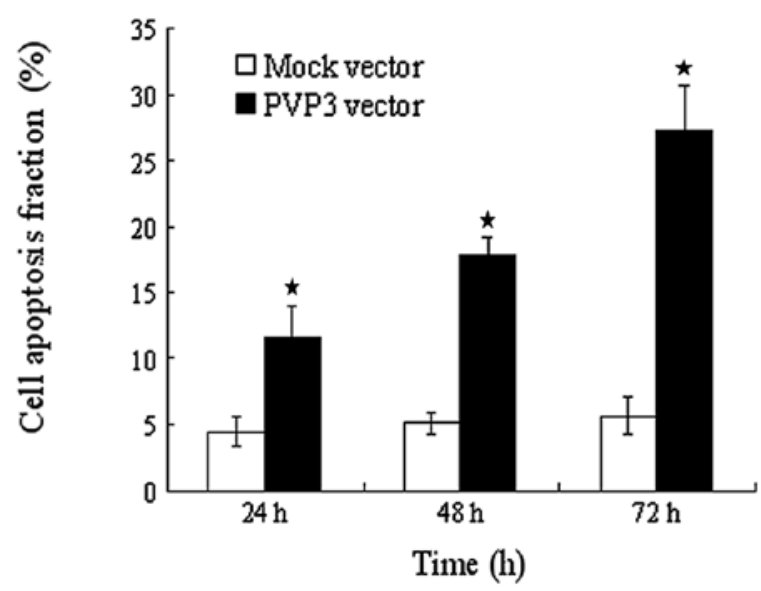

Figure 2. Expression of apoptin in transient transfected CNE-2 cells and results of cell proliferation and cell apoptosis test. (A) Western blot result shows apoptin expression in Mock vector or PVP3 vector transient transfected CNE-2 cells at 24, 48 and $72 \mathrm{~h}$. (B) Cell proliferation of Mock vector or PVP3 vector transfected CNE-2 cells was determined by MTT assay. (C) Cell apoptosis was stained using Annexin V and PI and assessed by flow cytometry, the result represents cell apoptosis of Mock vector or PVP3 vector transfected CNE-2 cells at 24, 48 and $72 \mathrm{~h}$. Columns, mean; bars, $\pm \mathrm{SD} ;{ }^{*} \mathrm{P}<0.001$; versus Mock vector transfected CNE-2 cells

show cell proliferation of $97.6 \pm 1.4,94.2 \pm 1.7$ and $92.3 \pm 2.1 \%$ at 24, 48 and $72 \mathrm{~h}$, respectively, while PVP3-CNE-2 cells show cell proliferation of $79.7 \pm 3.6,61.5 \pm 2.3$ and $52.4 \pm 3.8 \%$ at 24,48 and $72 \mathrm{~h}$ respectively, which indicates that expression of apoptin could restrain cell proliferation $(\mathrm{P}<0.001$, Fig. 2B). In addition, after transient transfection, 11.6 $\pm 2.4,17.8 \pm 1.4$ and $27.3 \pm 3.3 \%$ apoptotic cells were observed in PVP3-CNE-2 cells while $4.5 \pm 1.2,5.1 \pm 0.8$ and $5.7 \pm 1.4 \%$ apoptotic cells were observed in Mock-CNE-2 cells at 24, 48 and $72 \mathrm{~h}$, respectively $(\mathrm{P}<0.001$, Fig. 2C).

Apoptin reinforces the effect of PDT. To test whether apoptin has a synergistic effect in PDT, we used PVP3 stable transfection CNE-2 cells and its control cells to apply PDT treatment. 

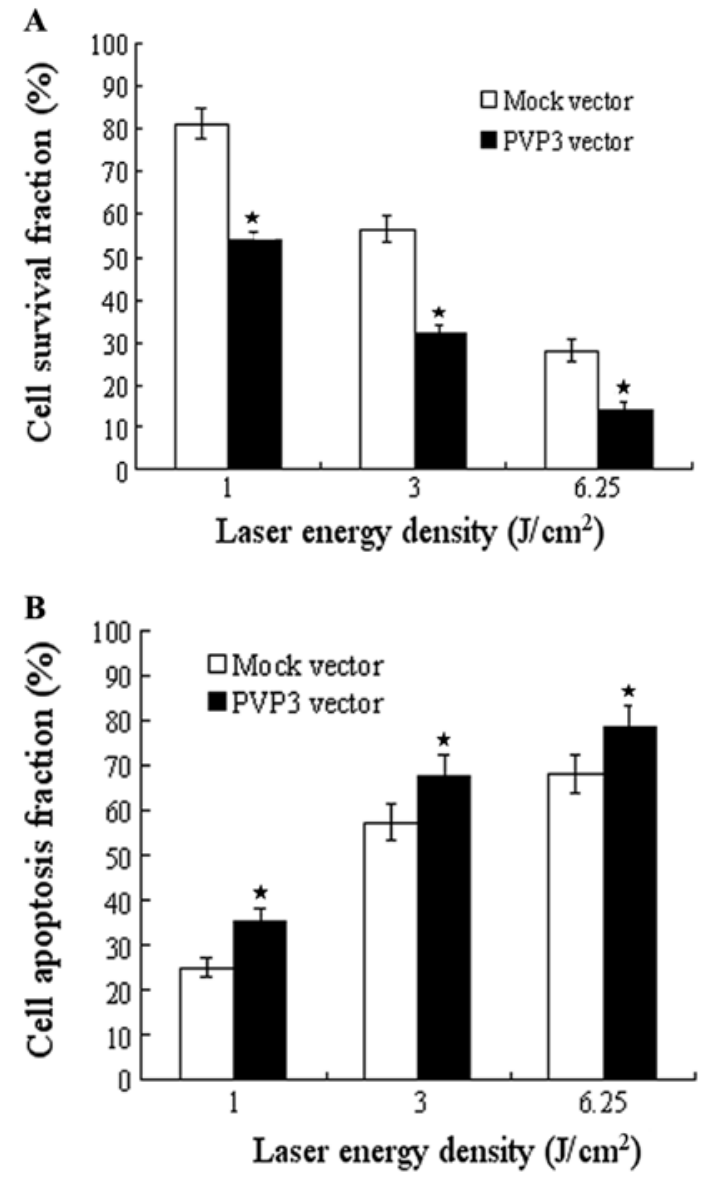

Figure 3. Cell proliferation and cell apoptosis of Mock vector or PVP3 vector transfected CNE-2 cells after PDT treatment. (A) Cell proliferation of Mock vector or PVP3 vector transfected CNE-2 cells under different laser energy density. (B) Cell apoptosis of Mock vector or PVP3 vector transfected CNE-2 cells under different laser energy density. Columns, mean; bars, $\pm \mathrm{SD} ;{ }^{*} \mathrm{P}<0.001$; versus Mock vector transfected CNE-2 cells.

The efficacy was evaluated by cell proliferation and apoptosis test. As showed in Fig. 3A, PDT significantly inhibited cell growth of both PVP3-CNE-2 cells and Mock-CNE-2 cells in different laser energy density $\left(1,3\right.$ and $\left.6.25 \mathrm{~J} / \mathrm{cm}^{2}\right)$ with maximal inhibition rate at $6.25 \mathrm{~J} / \mathrm{cm}^{2}$. The inhibition rate of PVP3-CNE-2 cells is much higher than that of Mock-CNE-2 cells in different laser energy density $(\mathrm{P}<0.001)$. Moreover, PDT significantly induced cell apoptosis of both PVP3-CNE-2 and Mock-CNE-2 cells in the different laser energy density and the apoptotic rate reached the maximum at $6.25 \mathrm{~J} / \mathrm{cm}^{2}$ (Fig. 3B). The apoptotic rate of PVP3-CNE-2 cells is much higher than that of Mock-CNE-2 cells in the different laser energy density $(\mathrm{P}<0.001)$.

Ultrastructural morphology. The ultrastructural morphology of PVP3-CNE-2 and Mock-CNE-2 cells after PDT treatment was investigated using TEM. As shown in Fig. 4A and B, compare with Mock-CNE-2 cells, PVP3-CNE-2 cells showed grievous deformation, nuclear condensation, but mitochondria and endoplasmic reticulum still clear without PDT. However, after PDT treatment, PVP3-CNE-2 cells showed more severe chromatin margination, swollen mitochondria and endoplasmic reticulum, nuclear fragmentation

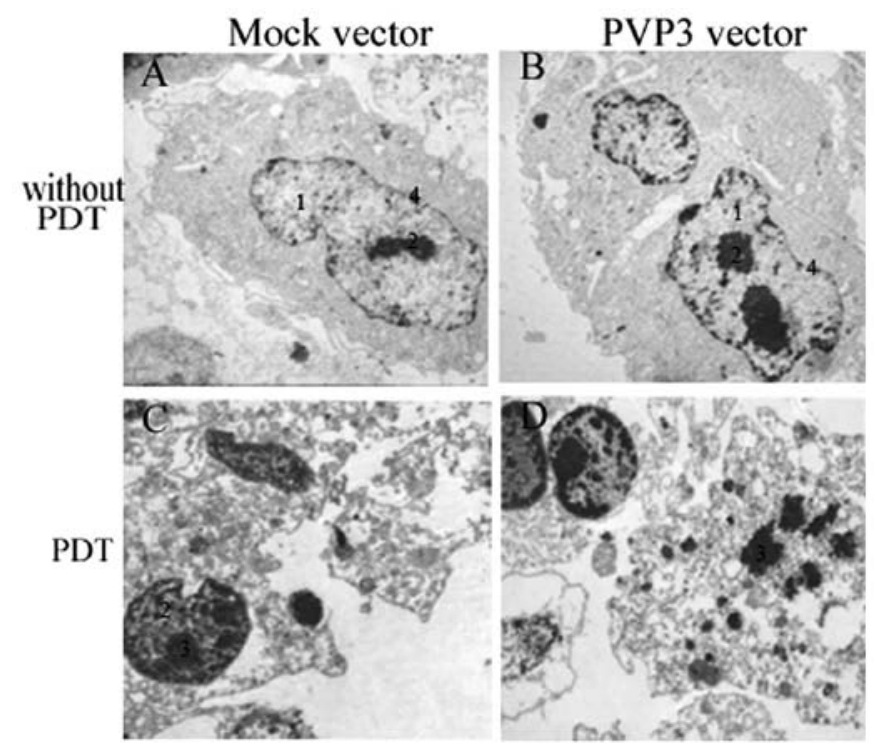

Figure 4. The ultrastructural morphology of Mock vector or PVP3 vector transfected CNE-2 cells after PDT treatment was investigated by TEM. (A) Mock vector transfected without PDT (x7000). (B) PVP3 vector transfected without PDT (x7000). (C) Mock vector transfected CNE-2 cells with PDT treatment (x7000). (D) PVP3 vector transfected CNE-2 cells with PDT treatment (x7000). 1 , nuclei; 2 , nucleolus; 3 , chromatin; 4 , karyotheca.
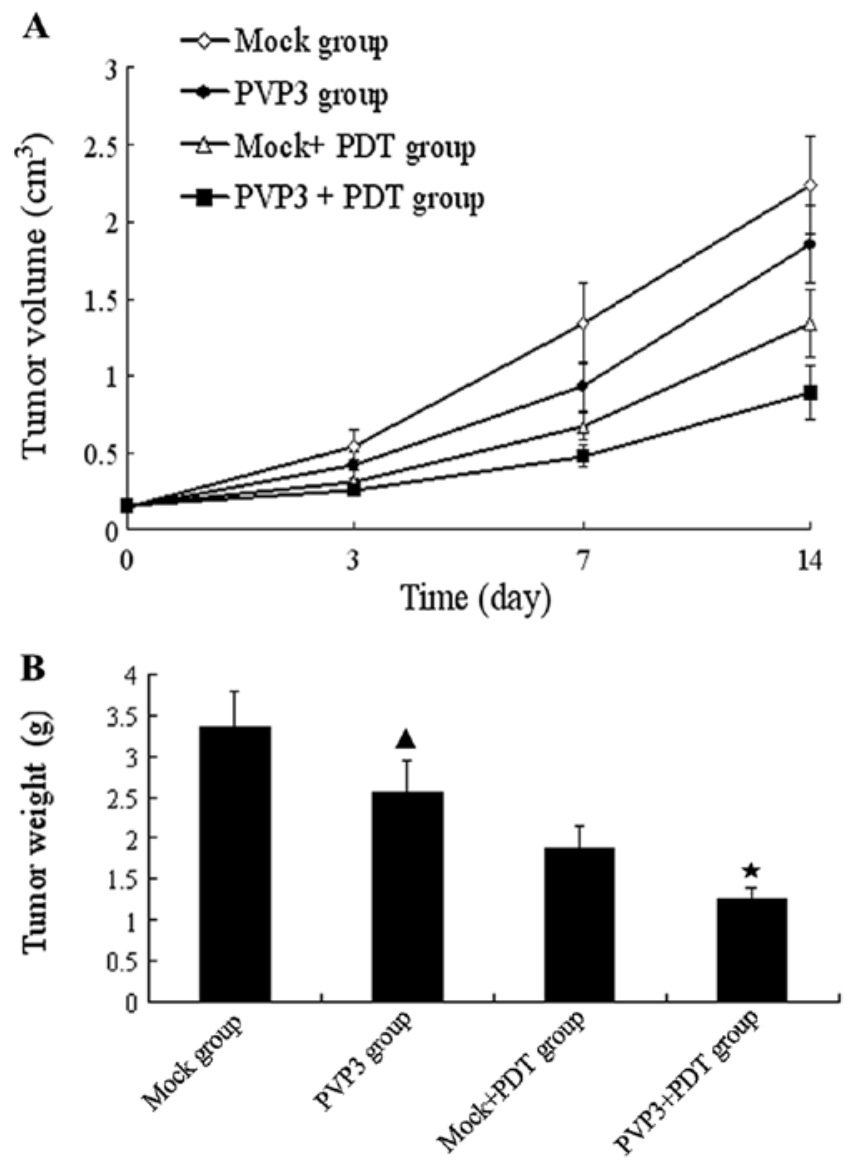

Figure 5. Tumor volume and weight of xenografts. (A) Tumor volumes of Mock group, PVP3 group, Mock + PDT group and PVP3 + PDT group on 3, 7 and 14 days. (B) Tumor weight of Mock group, PVP3 group, Mock + PDT group and PVP3 + PDT group on 14 days. Columns, mean; bars, \pm SD; ${ }^{\wedge} \mathrm{P}<0.001$; versus Mock group; ${ }^{\mathrm{P}}<0.001$; versus other three groups. 

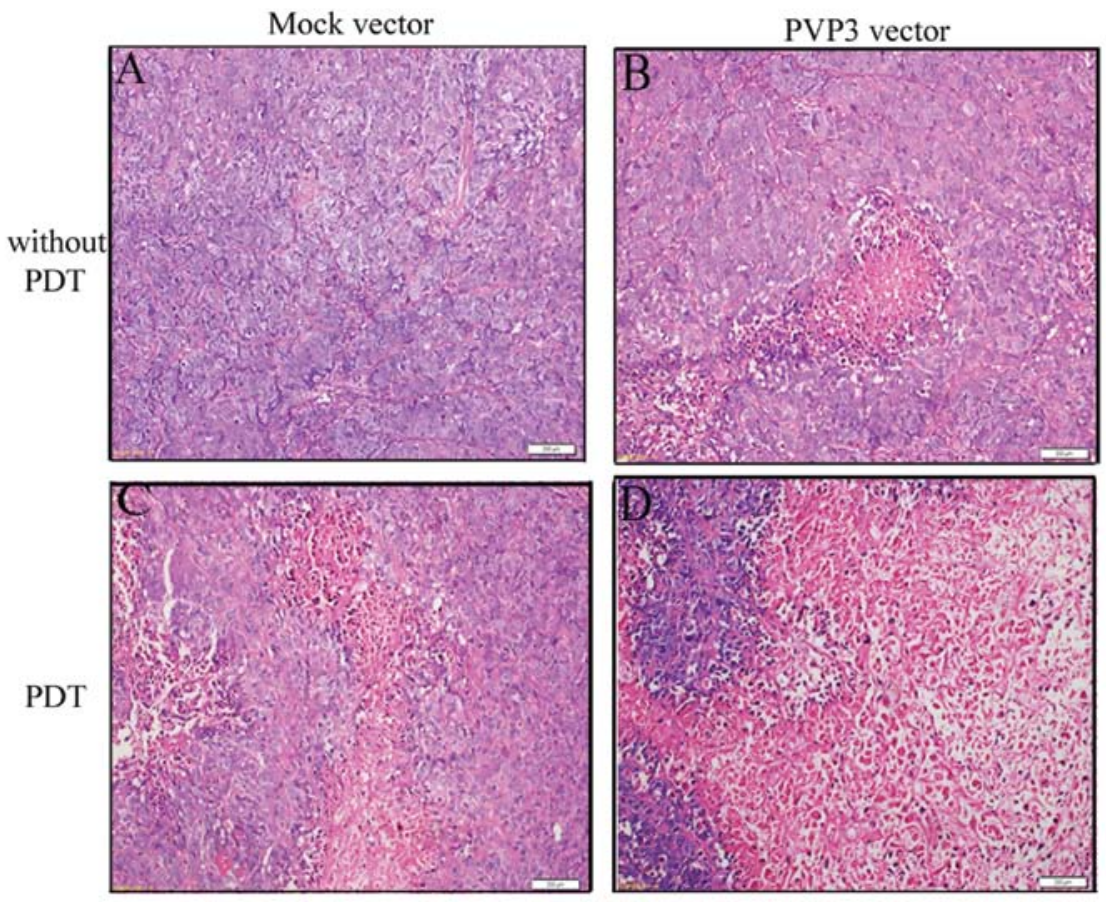

Figure 6. H\&E staining of slices by light microscopy x200. (A) There were numerous mitotic tumor cells around the blood vessels in the Mock group. (B) Numerous tumor cells and a few scattered necrotic areas were observed in PVP3 group. (C) Degeneration and pyknotic cells and a few scattered necrotic areas were observed in Mock + PDT group. (D) Numerous necrotic areas and some residual tumor cell islands were observed on PVP3 + PDT group.

and apoptotic bodies compared with Mock-CNE-2 cells in Fig. 4C and D.

Effects of VP3 and PDT therapy in vivo. 5-ALA dose of 100 $\mathrm{mg} / \mathrm{kg}$ and laser energy density of $100 \mathrm{~J} / \mathrm{cm}^{2}$ were selected for the in vivo studies. The mean tumor volumes before PDT were $0.150 \pm 0.026,0.148 \pm 0.021,0.155 \pm 0.031$ and $0.153 \pm 0.022 \mathrm{~cm}^{3}$ in Mock group, PVP3 group, Mock + PDT group and PVP3 + PDT group, respectively. After PDT treatment, we found that the tumor of PVP3 group was delayed and the nodules were smaller than in the Mock group. In addition, PVP3 + PDT group produced slow-growing tumors and smaller tumor sizes than the others. The mean tumor volumes on day 14 were $2.237 \pm 0.316$, $1.850 \pm 0.247,1.338 \pm 0.221$ and $0.887 \pm 0.174 \mathrm{~cm}^{3}$ in Mock group, PVP3 group, Mock + PDT group and PVP3 + PDT group, respectively (Fig. 5A). The tumor weight of PVP3 group was less than Mock group, and the tumor weight of PVP3 + PDT group was less than the others (Fig. 5B). These results suggest PVP3 + PDT group has the strongest xenograft inhibition of the four groups.

Histological findings. H\&E staining of slices was used to observe the xenograft morphological changes. As shown in the Fig. 6A, there were numerous mitotic tumor cells around the blood vessels and in the peripheral regions of the tumors in the Mock group and a few scattered necrotic areas were observed in PVP3 group (Fig. 6B). Extensive degenerated and pyknotic cells were observed in Mock + PDT group and PVP3 + PDT group after PDT (Fig. 6C and D). Additionally, there were numerous necrotic areas and some residual tumor cell islands on PVP3 + PDT group (Fig. 6D).

\section{Discussion}

PDT for the treatment of malignant tumors has been proved to be a feasible, safe and reliable method. It has many advantages. First, PDT on malignant tumors is highly selective, less damage to normal tissue or killing normal cells, high efficacy and celerity. Second, it is suitable for applying in the elderly and patients with severe complications or for those refused surgery for less impact on the liver, kidney and bone marrow system. Third, the operation of PDT is easy and simple, and PDT also has the advantage of direct effect of tumor location with high reliability (22-25).

However, this method also has some shortcomings. Since PDT is a kind of oxygen-dependent treatment, tumor hypoxia can be easily reduced by PDT, which greatly reduces the tumor-killing effect of PDT in return. The limitation of the depth also restricts the role of PDT in tumor treatment. How to enhance the antitumor effect of PDT is a serious challenge for researchers. In recent years, the combination of PDT and gene therapy is becoming a new strategy for the treatment of cancer. Currently, PDT/gene therapy is mainly used with immune genes, tumor suppressor gene and suicide gene combination, and this therapy has achieved good effect $(26,27)$.

In this study, we have demonstrated apoptin was able to significantly inhibit CEN-2 cells proliferation and enhanced cell apoptosis. To further investigate whether apoptin has a synergistic effect in PDT, we expressed apoptin in CNE-2 cells and dealt with PDT treatment. Our study has shown that apoptin with PDT treatment had stronger cell killing effect than apoptin or PDT treatment alone. We also found apoptin with PDT treatment induced severe ultrastructural 
morphology changes compare with apoptin or PDT alone. In addition, we demonstrated that apoptin with PDT treatment had the highest tumor-killing effect in vivo. These data clearly indicate that the tumor-killing effect of apoptin with PDT therapy is significantly stronger than single gene therapy or PDT.

Apoptin is located in the nucleus of tumor cells, it can associate with different interaction partners including death effector domain-associated factor (DEDAF), Nmi, anaphase-promoting complex/cyclosome (APC/C) and promyelocytic leukemia protein (PML) in the nucleus, which facilitates apoptin cracking the nucleus and induces tumor cells to apoptosis (28-31). On the other hand, the reactive oxygen species (ROS) produced by PDT can directly impact on the cell membrane, mitochondria, lysosomes, endoplasmic reticulum and golgi apparatus, which can induce tumor cell apoptosis. Apoptin with PDT therapy might through the nucleus and cytoplasm to promote apoptosis, therefore, tumor cell apoptosis is significantly increased in this kind of therapy.

In conclusion, our data showed that apoptin had certain cell killing effect in NPC cells, and apoptin with PDT therapy has significantly stronger tumor-killing effect than apoptin gene therapy or PDT alone.

\section{Acknowledgements}

This study was supported by Scientific Research Fund of Hunan Provincial Education Department.

\section{References}

1. Yu MC and Yuan JM: Epidemiology of nasopharyngeal carcinoma, Semin Cancer Biol 12: 421-429, 2002.

2. Chow E, Payne D, O'Sullivan B, Pintilie M, Liu FF, Waldron J, Warde $\mathrm{P}$ and Cummings B: Radiotherapy alone in patients with advanced nasopharyngeal cancer: comparison with an intergroup study. Is combined modality treatment really necessary? Radiother Oncol 63: 269-274, 2002.

3. Fritsch C, Goerz G and Ruzicka T: Photodynamic therapy in dermatology. Arch Dermatol 134: 207-214, 1998.

4. Roscetti G, Franzese O, Comandini A and Bonmassar E: Cytotoxic activity of Hypericum perforatum L on K562 erythroleukemic cells: differential effects between methanolic extract and hypericin. Phytother Res 18: 66-72, 2004.

5. Kiesslich T, Krammer B and Plaetzer K: Cellular mechanisms and prospective applications of hypericin in photodynamic therapy. Curr Med Chem 13: 2189-2204, 2006.

6. Kim CH, Chung CW, Choi KH, Yoo JJ, Kim do H, Jeong YI and Kang DH: Effect of 5-aminolevulinic acid-based photodynamic therapy via reactive oxygen species in human cholangiocarcinoma cells. Int J Nanomed 6: 1357-1363, 2011.

7. Kamoshima Y,Terasaka S, Kuroda S and Iwasaki Y: Morphological and histological changes of glioma cells immediately after 5 -aminolevulinic acid mediated photodynamic therapy. Neurol Res 33: 739-746, 2011.

8. Park JH, Moon YH, Kim DJ, Kim SA, Lee JB, Ahn SG and Yoon JH: Photodynamic therapy with hexenyl ester of 5 -aminolevulinic acid induces necrotic cell death in salivary gland adenocarcinoma cells. Oncol Rep 24: 177-181, 2010.

9. Los M, Wesselborg S and Schulze-Osthoff K: The role of caspases in development, immunity, and apoptotic signal transduction: lessons from knockout mice. Immunity 10: 629-639, 1999.

10. Schwerk C and Schulze-Osthoff K: Regulation of apoptosis by alternative pre-Mrna splicing. Mol Cell 19: 1-13, 2005.

11. Fischer U, Jänicke RU and Schulze-Osthoff K: Many cuts to ruin: a comprehensive update of caspase substrates. Cell Death Differ 10: 76-100, 2003.
12. Noteborn MH, Todd D, Verschueren CA, de Gauw HW, Curran WL, Veldkamp S, Douglas AJ, McNulty MS, van der EB AJ and Koch G: A single chicken anemia virus protein induces apoptosis. J Virol 68: 346-351, 1994

13. Maddika S, Mendoza FJ, Hauff K, Zamzow CR, Paranjothy T and Los M: Cancer selective therapy of the future: apoptin and its mechanism of action. Cancer Biol Ther 5: 10-19, 2006.

14. Noteborn MH: Chicken anemia virus induced apoptosis: underlying molecular mechanisms. Vet Microbiol 98: 89-94, 2004.

15. Heilman DW, Teodoro JG and Green MR: Apoptin nucleocytoplasmic shuttling is required for cell type-specific localization, apoptosis, and recruitment of the anaphase-promoting complex/ cyclosome to PML bodies. J Virol 80: 7535-7545, 2006.

16. Poon IK, Oro C, Dias MM, Zhang J and Jans DA: Apoptin nuclear accumulation is modulated by a CRM1-recognized nuclear export signal that is active in normal but not in tumor cells. Cancer Res 65: 7059-7064, 2005.

17. Backendorf C, Visser AE, de Boer AG, Zimmerman R, Visser M, Voskamp P, Zhang YH and Noteborn M: Apoptin: therapeutic potential of an early sensor of carcinogenic transformation. Annu Rev Pharmacol Toxicol 48: 143-169, 2008.

18. Tavassoli M, Guelen L, Luxon BA and Gäken J: Apoptin: specific killer of tumor cells? Apoptosis 10: 717-724, 2005.

19. Zhuang SM, Shvarts A, van Ormondt H, Jochemsen AG, van der Eb AJ and Noteborn MH: Apoptin, a protein derived from chicken anemia virus, induces p53-independent apoptosis in human osteosarcoma cells. Cancer Res 55: 486-489, 1995.

20. Burek M, Maddika S, Burek CJ, Daniel PT, Schulze-Osthoff K and Los M: Apoptin-induced cell death is modulated by Bcl-2 family members and is Apaf-1 dependent. Oncogene 25: 22132222, 2005.

21. Xie Y, Wei ZB, Zhang Z, Wen W and Huang GW: Effect of 5-ALA-PDT on VEGF and PCNA expression in human NPC-bearing nude mice. Oncol Rep 22: 1365-1371, 2009.

22. Krieger MD, Couldwell WT and Weiss MH: Assessment of long term remission of acromegaly following surgery. J Neurosurg 98: 719-724, 2003.

23. Barnes LD, Giuliano EA, Ota J, Cohn LA and Moore CP: The effect of photodynamic therapy on squamous cell carcinoma in a murine model: evaluation of time between intralesional injection to laser irradimion. Vet J 180: 60-65, 2009.

24. Yung A, Stables GI, Fernandez C, Williams J, Boiar RA and Goulden V: Microbiological effect of photodynarnic therapy(PDT) in healthy volunteers: a comparative study using methyl aminolaevulinate and hexyl aminolaevulinate cream. Clin Exp Dermatol 32: 716-721, 2007.

25. Su ZA, Yao K, Shen J, Jiang JK, Fang XY, Lin JJ and DU XH: Evaluation of photodynamic therapy in idiopathic choroidal neovascularization. Zhonghua Yan Ke Za Zhi 43: 509-513, 2007.

26. Luna MC, Chen X, Wong S, Tsui J, Rucker N, Lee AS and Gomer CJ: Enhanced photodynamic therapy efficacy with inducible suicide gene therapy controlled by the grp promoter. Cancer Res 62: 1458-1461, 2002.

27. Laden BP, Tang Y and Porter TD: Cloning, heterologous expression, andenzymological characterization of human squalene monooxygenase. Arch Biochem Biophys 374: 381-388, 2000.

28. Teodoro JG, Heilman DW, Parker AE and Green MR: The viral protein Apoptin associates with the anaphase-promoting complex to induce G2/M arrest and apoptosis in the absence of p53. Genes Dev 18: 1952-1957, 2004.

29. Danen-van Oorschot AA, Voskamp P, Seelen MC, van Miltenburg MH, Bolk MW, Tait SW, Boesen-de Cock JG, Rohn JL, Borst J and Noteborn MH: Human death effector domain-associated factor interacts with the viral apoptosis agonist Apoptin and exerts tumor-preferential cell killing. Cell Death Differ 11: 564-573, 2004.

30. Janssen K, Hofmann TG, Jans DA, Hay RT, Schulze-Osthoff K and Fischer U: Apoptin is modified by SUMO conjugation and targeted to promyelocytic leukemia protein nuclear bodies. Oncogene 26: 1557-1566, 2007.

31. Krieghoff-Henning E and Hofmann TG: Role of nuclear bodies in apoptosis signaling. Biochim Biophys Acta 1783: 2185-2194, 2008. 